\title{
Validitas Pengembangan Media Pembelajaran Blended Learning Berbasis Cloud Computing Tingkat Sekolah Menengah Atas Kota Padang
}

\author{
Monica Fransisca ${ }^{1}$, Yuliawati Yunus ${ }^{2}$ \\ Universitas Putra Indonesia "YPTK" Padang, Padang \\ monicafransisca@upiyptk.ac.id ${ }^{1}$, yuliawati_yunus@upiyptk.ac.id²
}

\begin{abstract}
The purpose of this research was to create an E-Learning as learning media with the implementation of Blended learning models combined with Cloud computing. These products will be designed interactively, effectively, and efficiently in accordance with lesson courses on subjects in high school with online system. The research method used is Research and Development with the stages of development of $4 D$ (Define, Design, Develop, Disseminate), in this research the product will be tested for feasibility by validity testing. Based on the results of the validity test conducted by system experts and content experts, it was found that this learning media can be categorized as feasible or valid to be used as a learning media in the Blended learning learning model in High School. The average percentage of the validity test results obtained was 90.6\%, which belongs to the very valid category. From the results of the validity test, it can be concluded that Blended learning which combined with cloud computing as learning media is suitable for use in all subjects at the level of the High School at Padang.
\end{abstract}

Keywords : Blended learning, Cloud computing, E-Learning

\begin{abstract}
Abstrak- Tujuan penelitian ini untuk membuat media pembelajaran berbentuk E-Learning dengan implementasi model pembelajaran Blended learning berbasis Cloud computing. Produk tersebut nantinya akan dirancang interaktif, efektif, dan efisien sesuai dengan GBPP pada mata pelajaran di Sekolah Menengah Atas secara online. Metode penelitian yang digunakan adalah Research and Development dengan tahapan pengembangan 4D (Define, Design, Develop, Disseminate), dalam penelitian ini produk akan diuji kelayakan dengan uji validitas. Berdasarkan pada hasil uji validitas yang dilakukan dengan pakar sistem serta pakar konten didapatkan hasil bahwa media pembelajaran ini dapat dikategorikan layak atau valid untuk digunakan sebagai media pembelajaran pada model pembelajaran Blended learning di Sekolah Menengah Tingkat Atas. Persentase rata-rata hasil uji validitas yang didapatkan adalah 90.6\%, yang termasuk ke kategori sangat valid. Dari hasil uji validitas tersebut maka dapat disimpulkan bahwa media pembelajaran Blended learning yang berbasis cloud computing ini layak digunakan untuk semua mata pelajaran di tingkat Sekolah Menengah Atas Kota Padang.
\end{abstract}

Kata kunci : Blended learning, Cloud computing, E-Learning

\section{PENDAHULUAN}

Media pembelajaran semakin berkembang pesat seiring dengan perkembangan dari teknologi saat ini. Salah satu bentuk perkembangan media pembelajaran pada saat ini adalah adanya media pembelajaran yang berbasis Cloud computing atau media pembelajaran berbasis online. Model pembelajaran yang mendukung media pembelajaran ini adalah Blended learning. Blended learning menurut [2] ialah pembelajaran hybrid, yaitu mencampurkan dan pengaturan pembelajaran yang divariasikan agar sesuai dengan tepat untuk 
memenuhi kebutuhan belajar peserta didik. Pencampuran tersebut dalam pembelajaran memang dibutuhkan untuk mencapai tujuan pembelajaran. Berdasarkan pengamatan yang dilakukan dapat diasumsikan bahwa mayoritas siswa di Sekolah Menengah Atas Kota Padang memiliki sarana untuk melakukan aktivitas online dengan perangkat pintar masing-masing. Selain itu sekolah juga menyediakan sarana dan prasarana untuk pembelajaran online tetapi kurang efektif penggunaannya bahkan belum tersedia media pembelajaran online. Selain itu jika guru berhalangan untuk hadir kegiatan pembelajaran tidak dapat terlaksana.

Cloud computing atau komputasi awan adalah gabungan pemanfaatan teknologi komputer ('komputasi') dan pengembangan berbasis Internet ('awan'). Awan (cloud) adalah metafora dari internet, sebagaimana awan yang sering digambarkan di diagram jaringan komputer. Sebagaimana awan dalam diagram jaringan komputer tersebut, awan (cloud) dalam Cloud computing juga merupakan abstraksi dari infrastruktur kompleks yang disembunyikannya. Media pembelajaran E-Learing berbasis Blended learning didalamnya terdapat materi ajar, animasi pembelajaran, videotutorial, soal berupa tes yang berkaitan dengan mata pelajaran per tingkatan kelas. Media pembelajaran ini mengimplementasikan sistem cloud computing sehingga siswa dapat mengakses E-Learning dimanapun mereka berada, sehingga pembelajaran tidak terikat di kelas saja. Melalui media pembelajaran ini guru juga dimudahkan dalam hal penyampaian materi, tugas, ataupun evaluasi akhir yang dapat diproses secara langsung oleh sistem.

Berdasarkan pada penelitian relevan yang sudah pernah dilakukan dapat diasumsikan bahwa media pembelajaran E-Learning dapat membantu meningkatkan kreativitas, keaktifan, serta hasil belajar siswa, hal ini sesuai dengan hasil penelitian relevan yang dirujuk dari [5]. Untuk lebih meningkatkan penggunaan dari E-Learning tersebut maka E-Learning tersebut dikombinasikan atau digabungkan dengan sistem cloud computing, agar siswa dapat mengakses $E$ Learning tanpa batas. Batasan masalah dalam penelitian ini adalah untuk mengetahui E-Learning berbasis Blended learning dapat membantu siswa untuk belajar secara mandiri dan memudahkan guru dalam menyampaikan materi pembelajaran pada setiap mata pelajaran serta memudahkan guru mendapatkan hasil belajar siswa secara otomatis dari sistem melalui evaluasi online. Penelitian ini ditujukan untuk Sekolah Menengah Atas di Kota Padang. Berdasarkan uraian tersebut dilakukan penelitian dengan judul "Analisa Dan Pengembangan Media Pembelajaran Blended learningBerbasis Cloud computingTingkat Sekolah Menengah Atas Kota Padang".

\section{METODOLOGI PENELITIAN}

\subsection{Blended learning}

Blended learning terdiri dari beberapa pengertian yaitu 1)perpaduan/integrasi pembelajaran tradisional dengan pendekatan berbasis web online; 2) kombinasi media dan peralatan yang digunakan dalam lingkungan $E$ Learning, dan 3) kombinasi dari sejumlah pendekatan belajar mengajar terlepas dari teknologi yang digunakan [1]. Tujuan pembelajaran blended learning adalah menggabungkan ciri-ciri terbaik dari pembelajaran di kelas (tatap muka) dan ciriciri terbaik pembelajaran online untuk meningkatan kualitas pembelajaran. 
Pembelajaran tatap muka dan pembelajan online terdapat kelebihan dan kelemahan masing-masing, sehingga jika kedua pembelajaran ini digabungkan maka berpotensi untuk saling menguatkan dan menutup kelemahannya [6]. Blended learning merupakan salah satu alternatif model pembelajaran yang harus dikembangkan oleh guru karena dapat membantu siswa meningkatkan prestasinya dalam pembelajaran [7].

\subsection{Cloud computing}

Cloud computing adalah suatu konsep umum yang mencakup SaaS, Web 2.0, dan tren teknologi terbaru lain yang dikenal luas, dengan tema umum berupa ketergantungan terhadap Internet untuk memberikan kebutuhan komputasi pengguna. Sebagai contoh, Google Apps menyediakan aplikasi bisnis umum yang dapat diakses melalui suatu penjelajah webdengan perangkat lunak dan data yang tersimpan di server. Cloud computingsaat ini merupakan tren teknologi terbaru, dan contoh bentuk pengembangan dari teknologi Cloud computing ini adalah iCloud.

\subsection{Metodologi Penelitian}

Pengembangan media pembelajaran Blended learning berbasis Cloud computing untuk siswa Sekolah Menengah Atas Kota Padang. Merupakan penelitian dan pengembangan (research and development). Metode penelitian pengembangan merupakan metode penelitian yang digunakan untuk menghasilkan produk tertentu, dan menguji keefektifan produk tersebut [3]. Untuk dapat menghasilkan produk tertentu digunakan penelitian yang bersifat analisis kebutuhan dan untuk menguji keefektifan produk tersebut supaya dapat berfungsi di masyarakat luas, maka diperlukan penelitian untuk menguji keefektifan produk tersebut. Sepuluh langkah pada metode penelitian dan pengembangan yang di tunjukan dalam bagan pada gambar 1 [3].

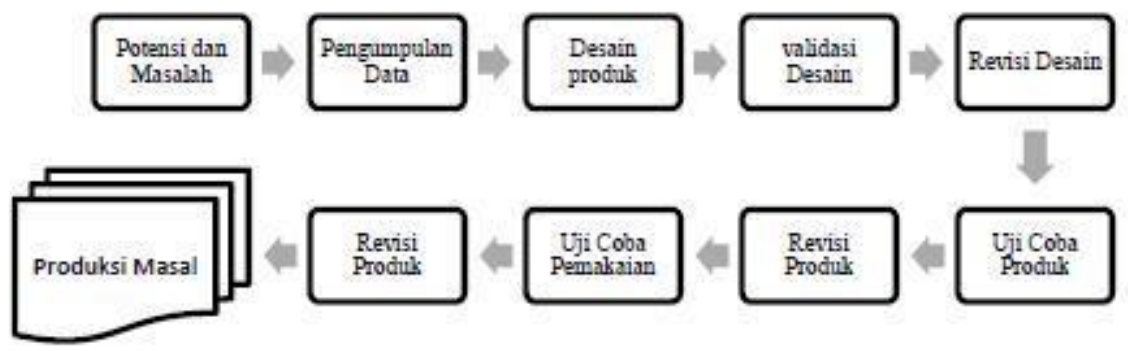

Gambar 1. Langkah-langkah penggunaan Metode Research and Development

\subsection{Prosedur Pengembangan}

(R\&D)

Media pembelajaran Blended learning berbasis Cloud computing dikembangkan dengan menggunakan four-D models yang dikembangkan oleh Thiagarajan, Semmel dalam [4] yaitu : 


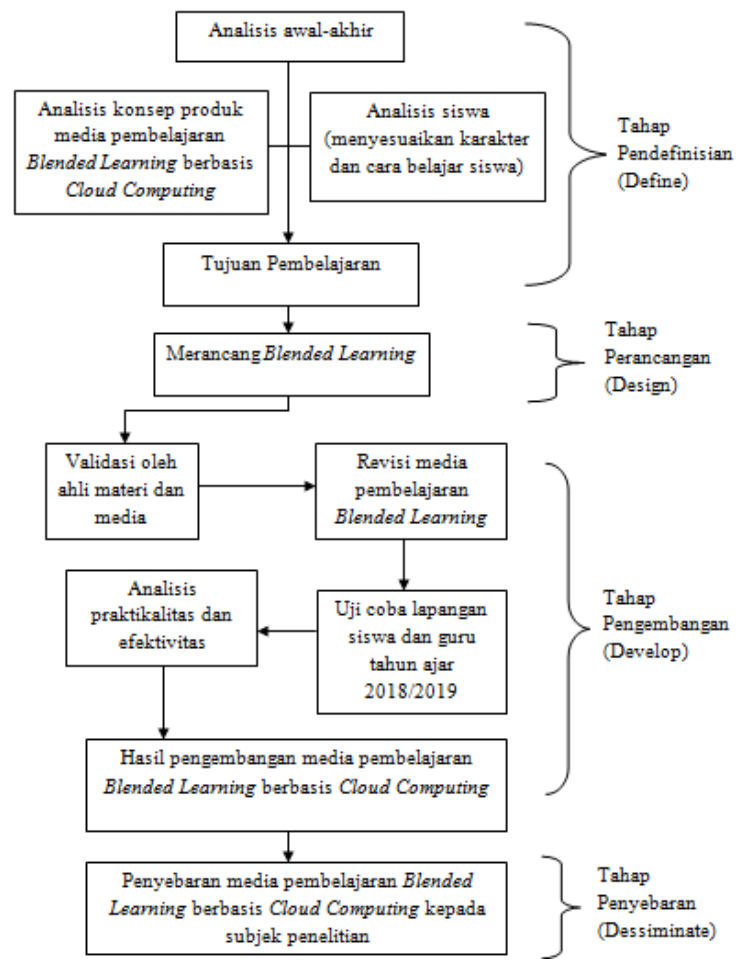

Gambar 2. Prosedur Penelitian

Tahap define mencakup beberapa langkah pokok, yaitu analisis siswa (learner analysis), analisis konsep (conceptanalysis) dan perumusan tujuan pembelajaran (specifying instructional objectives). Thiagarajan membagi tahap design dalam empat kegiatan, yaitu: constructing criterion- referenced test, media selection, format selection, initial design. Pada tahap develop dilakukan uji validitas yang dilakukan dengan ahli pakar yaitu pakar sistem dan pakar konten. Tahap disseminate merupakan tahap penggunaan perangkat yang telah dikembangkan pada skala yang lebih luas. Hasil blended learning dengan pengembangan menggunakan cloud computing yang sudah diuji kevaliditasannya akan di perbanyak dan layak untuk disebarkan.

\subsection{Pengambilan dan Pengujian Data}

Pengambilan data uji validitas dilakukan dengan menggunakan instrument Angket yang merupakan assessment yang dinilai oleh para ahli diantaranya pakar sistem informasi, pakar kontent e-learning dan pakar pembelajaran jarak jauh (Blended Learning), sebanyak 5 Orang pakar.

\section{HASIL DAN PEMBAHASAN}

\subsection{Hasil Perancangan Blended-learning Berbasis Cloud Computing}

Berikut merupakan tampilan Beranda e-learning pada satu sekolah di Kota Padang yaitu; SMA Negeri 4 Padang, dapat di lihat pada gambar 3. 


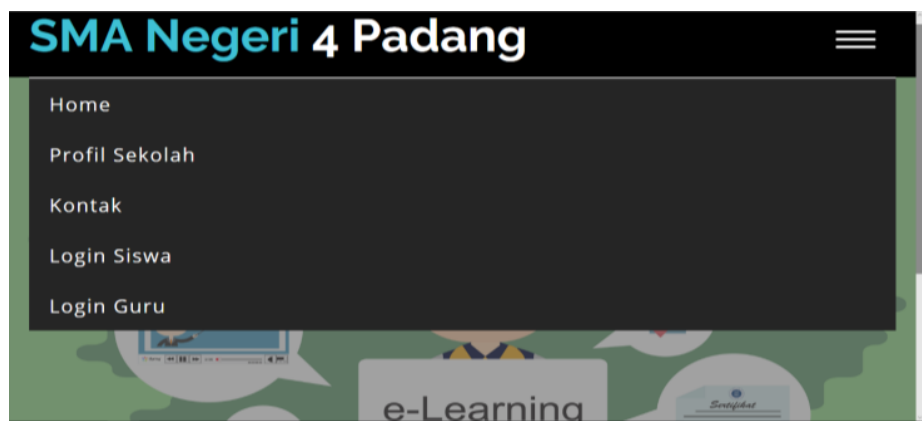

Gambar 3. Tampilan Beranda Blended Learning

Tampilan Beranda ini merupakan halaman akses untuk pengguna Siswa ataupun guru serta akses informasi tentang Sekolah yang bersangkutan. Berikut Tampilan halaman akses Guru, dapat dilihat pada gambar 4.

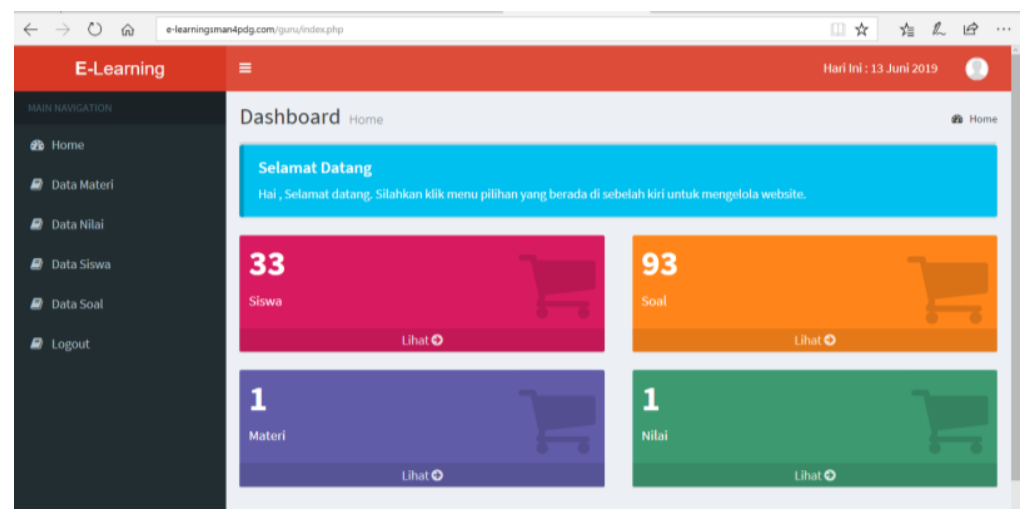

Gambar 4. Tampilan Akses Guru

Tampilan Akses guru memuat kegiatan yang dilakukan oleh guru sebagai penunjang kegiatan pembelajaran seperti input Materi, Nilai Siswa, Akses Absensi siswa yang Online pada saat kegiatan e-learning dan menyajikan evaluasi kepada siswa. Kemudian berikut merupakan Akses Siswa sebagai pengguna, dapat dilihat pada gambar 5 .

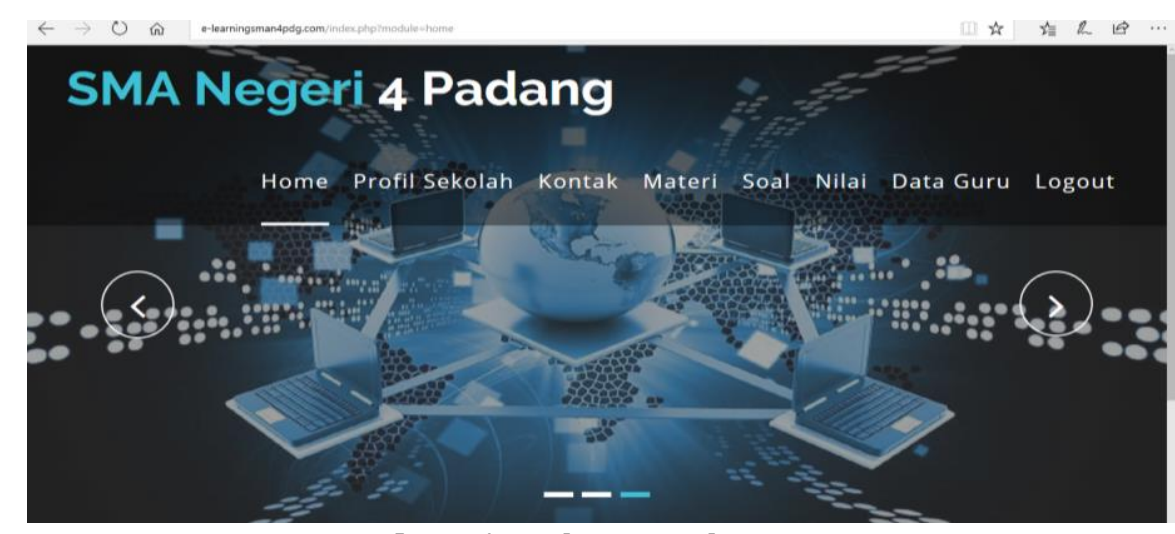

Gambar 5. Halaman Akses siswa

Halaman ini berisikan Kegiatan pembelajaran yang dilakukan oleh siswa, pada tampilan ini disajikan informasi tentang Sekolah, Profil sekolan, Materi yang 
disajikan Oleh Guru (baik materi yang ditampilkan ataupun yang bisa didownload oleh siswa), kemudia menu soal yang sebgai evaluasi kegiatan pembelajaran berbasis Blended learning, menu siswa dan data guru yang mengajar.

\subsection{Pembahasan dan Hasil Uji Validitas}

Berdasarkan pada hasil uji validitas dengan para ahli pakar untuk pakar sistem dan pakar konten serta pakar pembelajaran Jarak jauh sebanyak 5 Orang didapatkan rata-rata hasil uji validitas adalah 90.6\%. Penilaian hasil uji validitas ini berdasarkan pada kriteria: kelayakan isi, komponen bahasa, komponen penyajian, dan komponen kegrafikan dengan total jumlah butir pertanyaan sebanyak 20 buah. Hasil uji validitas tersebut dapat dilihat pada hasil pengolahan data yang berbentuk diagram distribusi frekuensi. Dapat dilihat pada gambar 6

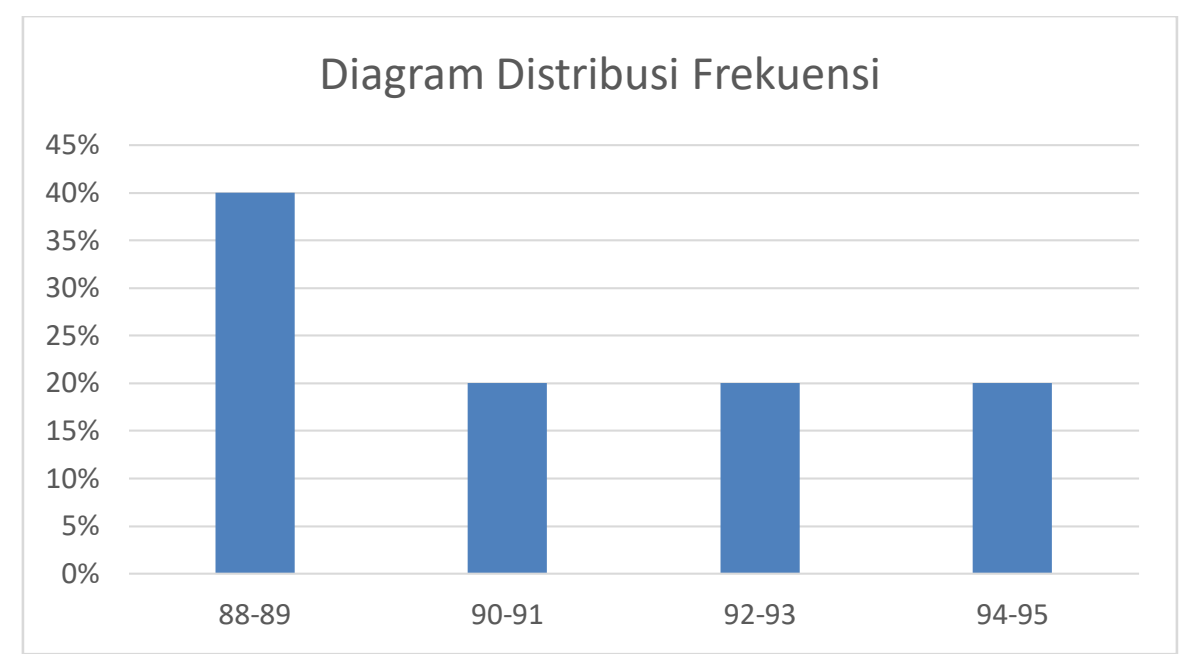

Gambar 6. Diagram Distribusi Frekuensi Hasil Uji Validitas.

\section{KESIMPULAN}

Pembelajaran Blended Learning merupakan pembelajaran yang cocok pada era revolusi industri 4.0, sehingga perlunya dibuat sebuah sistem berbasis Blended Learning dalam kegiatan belajar mengajar sekolah, sistem yang dimaksud merupakan sistem e-learning yang dibuat sedemikian mungkin disesuaikan dengan kebutuhan sekolah. Sistem yang baik perlu dilakukan pengujian oleh beberapa pakar/ahli dalam bidangnya, dalam penelitian ini pakar yang disebut Pengujian Validitan atau kelayakan sistem sebelum digunakan. Pada penelitian ini pakar yang dipakai sebanyak 5 orang dengan hasil penilaian sistem 90,6\% berada pada kriteria Sangat Valid digunakan. Setelah dilakukan pengujian Validitas nantinya akan dikembangkan ke pada pengujian selanjutnya, yaitu uji kepraktisan dan keefektifan langsung pada objek penelitiannya disekolah-sekolah khususnya Kota Padang.

\section{DAFTAR PUSTAKA}

[1] Hidayati, R. . (2013). Blended learning untuk menyambut implementasi kurikulum 2013. Dikutip dari http://jatim.kemenag.go.id/file/file/mimbar324/rflx1378291007.pdf

[2] Smaldino, S, "Insctuctional technology and media for learning ninth edition", , PEARSON Merrill Prentice Hall, Ohio, 2008. 
[3] Sugiyono, "Metode Penenlitian Kuantitatif, Kualitatif, dan R\&D”, Alfabeta, Bandung, 2013.

[4] Trianto, "Mendesain Model Pembelajaran Inovatif-Progresif ", Kencana, Jakarta, 2009.

[5] Utami, I.S, "Pengujian Validitas Model Blended learning di Sekolah Menengah Kejuruan", Jurnal VOLT FKIP Untirta Vol 2, Nomor 1, pp 1-10, Oktober 2017.

[6] Yusuf, "Mengenal blended learning", Lentera Pendidikan.14(2): 232-242, 2011.

[7] Vernadakis, I, "The impact of blended learning and traditional instruction in student's performance. Procedia Technology", 1:439-443, 2012. 